\title{
Mica Filled PVC Composites: Performance Enhancement in Dielectric and Mechanical Properties with Treated/Untreated Mica of Different Particle Size and Different Concentration
}

\author{
S. P. Deshmukh and A. C. Rao \\ General Engineering Department,Institute of Chemical TechnologyMatunga, Mumbai \\ 400019, India. \\ E-mail: sp_deshmukh@yahoo.co.in \\ E-mail: ac.rao@ictmumbai.edu.in
}

\begin{abstract}
Polyvinyl chloride (PVC) of different grades is the second most commonly used polymer for fabrication of electric cables and wires after polyethylene. Cables of domestic and industrial use of various capacities are fabricated using different compounds of PVC. Mica is useful particulate filler extensively used to enhance the performance of many polymeric materials. It surface resistance and arc resistance improving its mechanical properties. In the present research work mica filled PVC composites of different concentrations were prepared using untreated and surface treated water ground mica of different particle size. Mica filled PVC composites were compounded for various compositions and test samples were prepared using compression moulding process. These samples were tested for electrical insulation and mechanical properties. The results shows enhancement in dielectric properties with improvement in Young's modulus, stiffness, reduction in elongation at break and slight increase in shore D hardness of composites. Scanning electron microscopy was used to test the morphology of the samples which has shown proper distributions and adhesion of the filler mica in PVC matrix. There was some effect of surface treatment of mica on its mechanical and dielectric properties of the composite.
\end{abstract}

Key words: Polyvinyl chloride (PVC), Water ground mica (WGM), Scanning electron microscope (SEM), PVC composite

\section{INTRODUCTION}

PVC is the most used polymer for general purpose domestic and industrial wiring, cable insulation and sheathing, taking about $70 \%$ of the compounded polymers used by the industry and it is likely to retain its importance among thermoplastic compounds [1,2]. It is readily 
miscible and compatible polymer with large number of molecular weight compounds to give vide differing mechanical and electrical properties from rigid to flexible compounds. Compounded PVC, more than any other plastic material, is considered most versatile plastic. It can be formulated to be non-toxic, nonflammable, light, stable and stain resistance through proper formulations. As material for ultimate product, compounded PVC cables and sheets are manufactured by extrusion process. Mica is extensively used as reinforcing filler for plastic composites because of its influence on the physical, mechanical and electrical properties of composites [3-6]. Mica has the modulus of $172 \mathrm{GN} / \mathrm{m}^{2}$ against $73 \mathrm{GN} / \mathrm{m}^{2}$ of the glass flakes, hence its choice and is used as particulate filler for reinforced composite. Mica has excellent chemical and corrosion resistance, good electric properties, low thermal expansion and cause less wear and abrasion to the processing equipment.

Gupta et al [7] has found in their studies that microcracks resulted from internal stresses of mica filled composites have adequate strength and electrical properties. High modulus mica fillers does not distort during cooling of the composite and consequently leads to brittle matrix cracks. These microcracks in composite materials arise mainly from debonding of the interface between mica and resin. It has been found that dimensional stability of the mica filled composites was more compared to wood and glass filled composites [8,9]. The properties of the mica filled composites are determined by component properties, composition, structure, particle-particle interaction, and particle matrix interaction [10]. Mica agglomeration, distribution, wetting and adhesion with polymer resin determine the composite properties. Upgrading mica by increasing aspect ratio and coupling efficiency and combining mica with other fibres can improve the reinforcing effect of the composites [11].

Studies by P.Bajaj et al ${ }^{[12],}$ reveals that mica filled composite sheets can utilize the planner reinforcing properties of mica, although other fabrication techniques are also used in fabrication of part of these composite. Processing, applications, and properties of mica filled composites has been reviewed extensively in many references $(12,13)$. Use of mica as a filler in composite leads to initial breakage and delamination of it's particles during processing, changing it's size significantly influence the final properties of the composites.

Mica filled polymer composite materials shows significant improvement in dielectric properties of the plastics [14]. These changes in the electrical properties of the mica filled polymer composites make them suitable for their use in electrical insulation applications on large extent. The study carried out on the mica filled PVC composites of varying size and different filler concentration reveals changes of the mechanical and electrical properties such as stiffness, tensile strength, dielectric strength, surface resistance etc. of the composites $(15,16)$.

\section{EXPERIMENTAL}

\subsection{Materials}

Different PVC mica composites were prepared for research work to develop the final compression moulded sheets. PVC resin of k 57 grade of Reliance Industries ltd., India was 
used for the research work. INSTABEX C-11, one pack stabilizer ( 66-72\% $\mathrm{Pb}, 71.1$ 77.55\% PbO, 3.2 - 3.8 Sp. gr. and 1\% maximum moisture) supplied by m/s Aryavart Chemicals Pvt. Ltd India was used as the stabilizer. Stearic acid supplied by $\mathrm{m} / \mathrm{s}$ Godrej Industries ltd was used as lubricant. DOP was used as a plasticizer for compounding. Water ground high aspect ratio( 20 -40) lustrous filler mica of WGM 101, WGM 202, and WGM SIL supplied by M/s Galaxy Corporation, Mumbai, India was used in different proportions starting from 10 grams to maximum 50 grams in the range of 10 grams in every stage. Virgin test samples without filler were prepared with the PVC and additives such as stabilizer, lubricant and plasticizer. . Silquest 11009(3-aminopropyltriethoxysilane) silane coupling agent, supplied by Crompton specialties Purto Rico, USA was used for Surface treatment of mica.

\subsection{Compounding}

For all composite formulations weight of resin, stabilizer, lubricant and plasticizer were kept uniform and mica was added as filler to this mix in different weight proportions. The research work was aimed to determine use of mica as filler in PVC to develop composite with improved mechanical and electrical properties. The weight proportions of the resin, lubricant, stabilizer and plasticizer were selected based on the PVC cable formulations and is given in Table 1. Water ground mica WGM 101, WGM202 and WGM SIL of 150, 74 and 44 micron particle size and surface area of 1.4, 2 and $4.8 \mathrm{~m}^{2} / \mathrm{gm}$ respectively was used in formulations.

Table 1. Mica PVC Composite formulation for study

\begin{tabular}{|c|c|}
\hline $\begin{array}{c}\text { Compounding } \\
\text { material }\end{array}$ & $\begin{array}{c}\text { Weight in } \\
\text { grams }\end{array}$ \\
\hline Mica & 10 to 50 \\
\hline PVC Resin & 100 \\
\hline Liquid DOP & 50 \\
\hline INSTABEX C-11 & 4 \\
\hline Stearic Acid & 1 \\
\hline
\end{tabular}

PVC resin, INSTABEX C-11, mica, and stearic acid were dry blended using high-speed mixer for five minutes. Liquid DOP was added in two to three stages during dry blending. The dry blending process was carried out at $105^{\circ} \mathrm{C}$. 
Dry blended mixtures were melt compounded using Haake Rheocord 9000 batch compounder. Roller blades Rheomix 600 were used for compounding of the mix. Dry blended PVC mix of 60-gram weight was compounded at $180^{\circ} \mathrm{C}$ temperature for 5minutes with 60r.p.m. roller speed in different batches. Ten batches of such compound were processed with this machine for each formulation of composite. Processed PVC mix was found non sticky and was able to remove from blades easily. The compounded mix was then cooled to room temperature before it was packed and labelled.

\subsubsection{Compression molding}

The compounded PVC composite was dried in oil heated electric oven at $105^{\circ} \mathrm{C}$ for the period of one hour to remove the moisture before it is compression moulded making test sheets. The compression-moulded sheets of 90 gm weight and $180 \times 180 \mathrm{~mm}$ size with $2 \mathrm{~mm}$ thickness were fabricated. The hydraulic compression-moulding machine was used for the study. The compression moulds were heated to temperature of $180^{\circ} \mathrm{C}$ for moulding of the test samples. After the molding of sheet the mold and sheet were cooled to the $40^{\circ} \mathrm{C}$ at the process pressure of $130 \mathrm{~kg} / \mathrm{cm}^{2}$ allowing curing of sheets. These sheets were then used for determining mechanical and electrical properties of the PVC composites.

\subsubsection{Surface treatment of filler}

Diluted solution of ethanol/water (90\%/10\%) and Silquest A-1100 in 80/20 weight proportion was prepared. 200gm WGM 101, WGM 202 and WGM SIL mica were prewetted with 16 $\mathrm{ml}, 12 \mathrm{ml}$, and $8 \mathrm{ml}$ of ethanol and silquest solution respectively and thoroughly mixed and dried at $105^{\circ} \mathrm{C}$ at $2400 \mathrm{rpm}$ for 10 minutes. The treated mica was dried in air circulating oven at $105^{\circ} \mathrm{C}$ to remove diluent for one hour before mixing with PVC resin and other ingredients of composites.

\subsubsection{Mechanical properties}

Mechanical properties of the test specimen were evaluated ae per ASTM D 638 using Universal Testing Machine LR 50K from Lloyd Instruments Ltd., U.K. at cross head speed of $50 \mathrm{~mm} / \mathrm{min}$. Five test samples of each composite were tested for finding average values of mechanical properties. Shore D hardness test was carried out on test samples and results are analyzed.

\subsubsection{Electrical properties}

The dielectric strength was investigated as per ASTM D 149 using Zaran Instruments (India) with $2 \mathrm{~mm}$ thick test samples of the composites. The voltage for this test was slowly increased to penetrate the sample and its maximum values were noted. The instrument was having input configuration of $240 \mathrm{~V}, 50 \mathrm{~Hz}, 1 \mathrm{PH}$ with $0-50 \mathrm{~K} \mathrm{~V}$ output at $100 \mathrm{~mA}$ with 15 minutes rating. Arc resistance of test specimen was carried out as per ASTM D 495-89, which is high voltage, low current test. Arc resistance was determined using Zaran Instrument with $2 \mathrm{~mm}$ 
thick composite sheets. Surface resistance tests were carried out as per ASTM D 257 using HP 4339 B high resistance meter of Hewlett Packard, surface testing machine. The Electrode diameter machine was $2.5 \mathrm{~cm}$ with output voltage of $500 \mathrm{~V}$ and the current limit of $500 \mu \mathrm{A}$. Dielectric constant of the composites were measured using Precision impedance analyze of Wayne Kerr. U.K. with Dc current with voltage range of 0 to $40 \mathrm{~V}$ and frequency of $20 \mathrm{~Hz}$ to $20 \mathrm{MHz}$ as per ASTM D150.

\subsubsection{Morphological properties}

SEM was used to study morphology of the mica PVC composites. SEM studies of tensile test fractured and liquid nitrogen fractured samples were carried out using JSM-6380LA Analytical Scanning microscope of Joel make, Japan. The Samples were sputter coated with platinum to increase the surface conductivity using JFC-1600 auto fine coater of Joel Make Japan.. The digitized images of the samples were recorded and studied.

\section{RESULTS AND DISCUSSION}

\subsection{Elongation at Break}

It is observed that elongation at break of test samples decreases with increasing concentration of filler loading of each type of PVC composite. This decrease in elongation is attributed to restriction of polymer chain movements. The extent of filler dispersion plays an important role in changing properties of mica filled composite. Even though, there was proper filler and matrix bonding, this bonding appeared unable to withstand shear strain and elongations at rupture of mica filled composites failing it catastrophically.

The trend of elongation of the PVC composite is shown in figure 1. It shows that, as the concentration of filler increases the polymer chain moment and displacement due to applied force reduces. From the figure it is found that in reinforcement matrix there will be a distribution of tensile and compressive micro stresses. Tensile stresses more likely at low volume fractions, and it is possible that these stresses may generate interface cracking. In the flakes, the possibility of a tensile stress near the periphery of the flakes is low. However, between two neighbouring flakes and away from the edges, a tensile stress is likely to develop to maintain overall equilibrium. Strength reduction in mica filled PVC composite in relation with virgin (neat) PVC could be attributed to formation of micro cracks in the resin matrix due to the internal stresses developed during curing and difference in the thermal shrinkage of PVC and mica.

The lowering of extension of the Mica filled PVC composite may be associated with weak fibre matrix adhesion. The weak filler polymer matrix has less elongation at break as compared neat polymer. More filler content of the polymer matrix reduces its elongation considerably. The reduction in elongation improves the Young's modulus and stiffness of the composite which will be beneficial for use of this materials in wire and cable applications for outdoor applications improving the life of the insulation. 


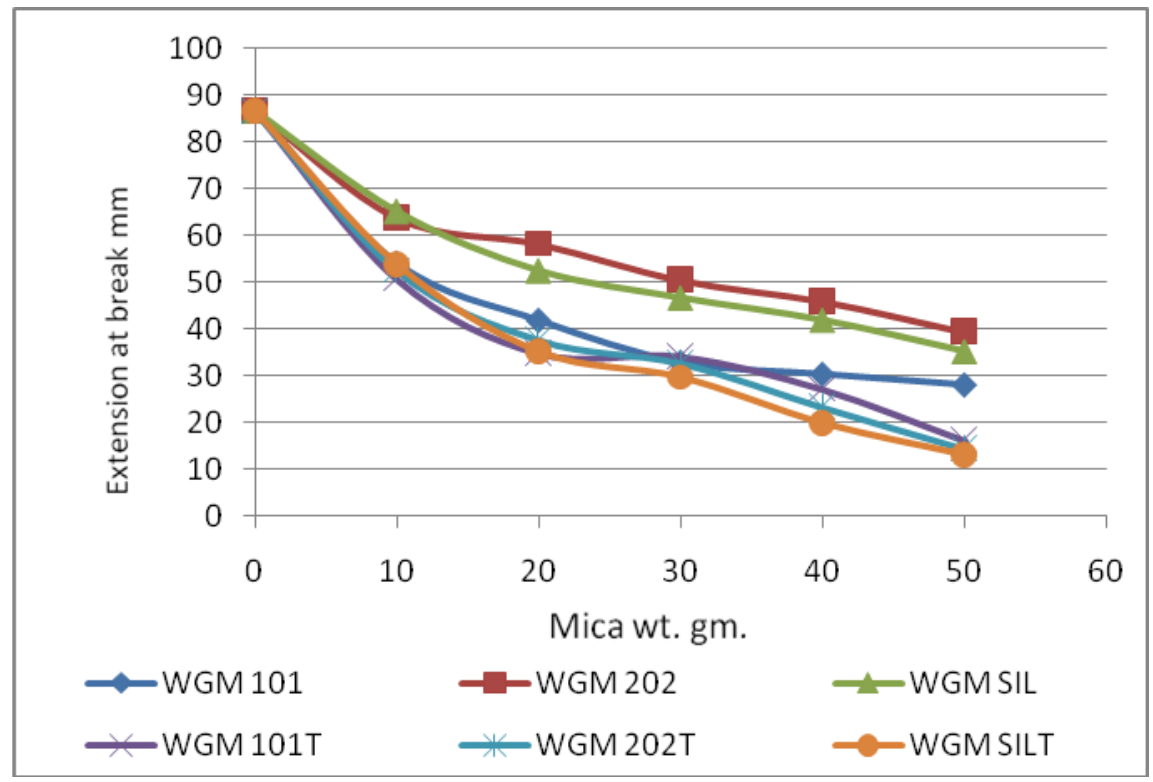

Figure 1. Elongation of Mica Filled PVC Composites

\subsection{Electrical Properties}

The results obtained for the dielectric strength, surface resistance and arc resistance and dielectric constant for test specimens with increasing mica content in PVC are shown in figure 2 to 4. Small mica addition in PVC acts as a intermolecular plasticizer and is able to penetrate the molecules of the PVC, leading to chain separation. This leads to the increase in the some of the dielectric properties of the materials. At higher loading of mica, it acts as an intramolecular plasticizer, where the mica molecules distributed in a inner aggregate space. This hinders the polymer chain elongation and consequently reduces some the dielectric properties.

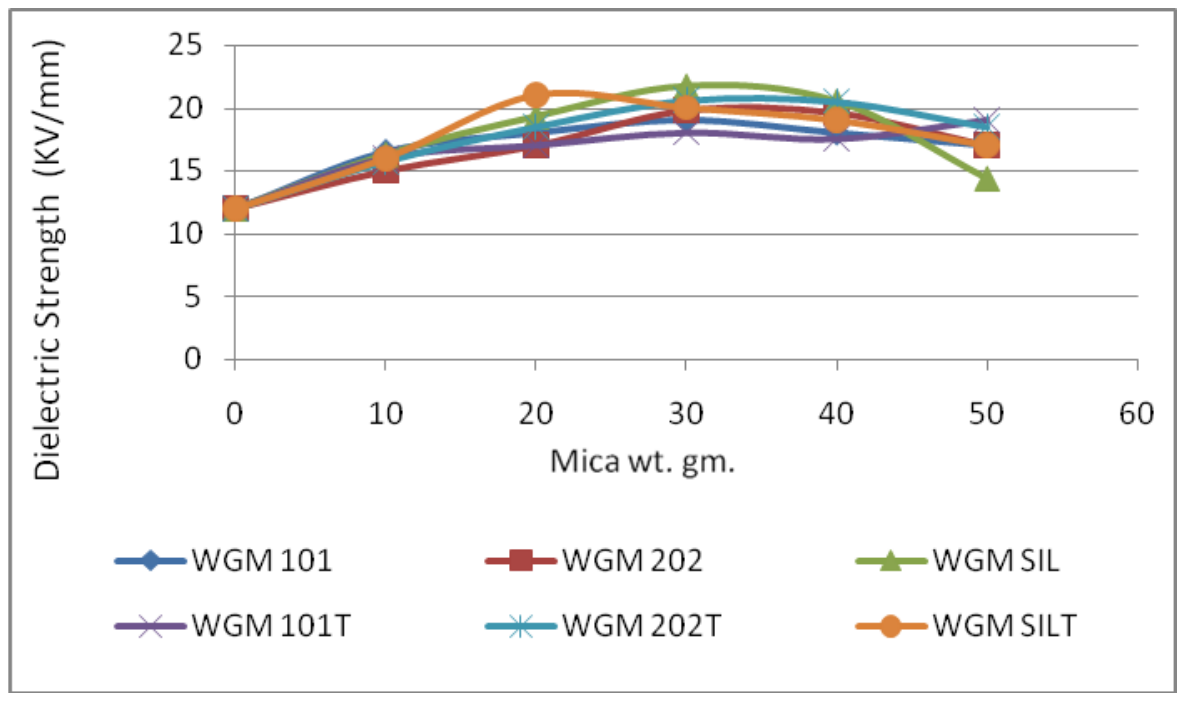

Figure 2 Dielectric Strength of Mica filled PVC composites. 
The surface resistance, dielectric strength and arc resistance, and dielectric constant of the untreated and surface treated mica filled PVC composites containing 10 to 50 parts by weight of mica flakes of different sizes were measured on five samples of each composition and average of the reading are tabulated for analysis purpose. Form the figure 2 it has been shown clearly that the dielectric strength of the mica filled PVC composite has been increasing as expected from the virgin ( neat) PVC matrix without any filler contain as mica has good electric resistance. For WGM SIL mica of $44 \mu \mathrm{m}$ the percent increase was as high as $187.5 \%$ as against the reduction by $17 \%$ for the same type of mica. For other mica fillers the dielectric strength has been found increased considerably. This may be explained as follows. As the SEM micrographs (figures 7-11) shows, the resin is more densely packed in the sample containing 30 and 40 parts by weight of mica filler, while in the samples of low loading of mica, the resin is relatively loosely packed. Since dense packing will hinder displacement of the dipoles and also hinder the accumulation of charges at the filler resin interphase, and since dielectric strength is directly related to these two factors the rate of increase is observed.

Presence of chlorine atoms in the polyvinyl chloride molecules determines an increased polarity in comparison with other polymers such as polyolefin. Electrical resistivity is the most important representative characteristic for cable insulation. It depicts the structural integrity under the action of the electrical field, and electron availability as charge carrier. For PVC the energy transfer from it is consumed for bond scission which is followed by the remote of hydrochloric acid, and the increase in the unsaturation level, or by cross linking. Consequently the electrical resistance will take certain values according to the modifications of the composition of the insulating material.

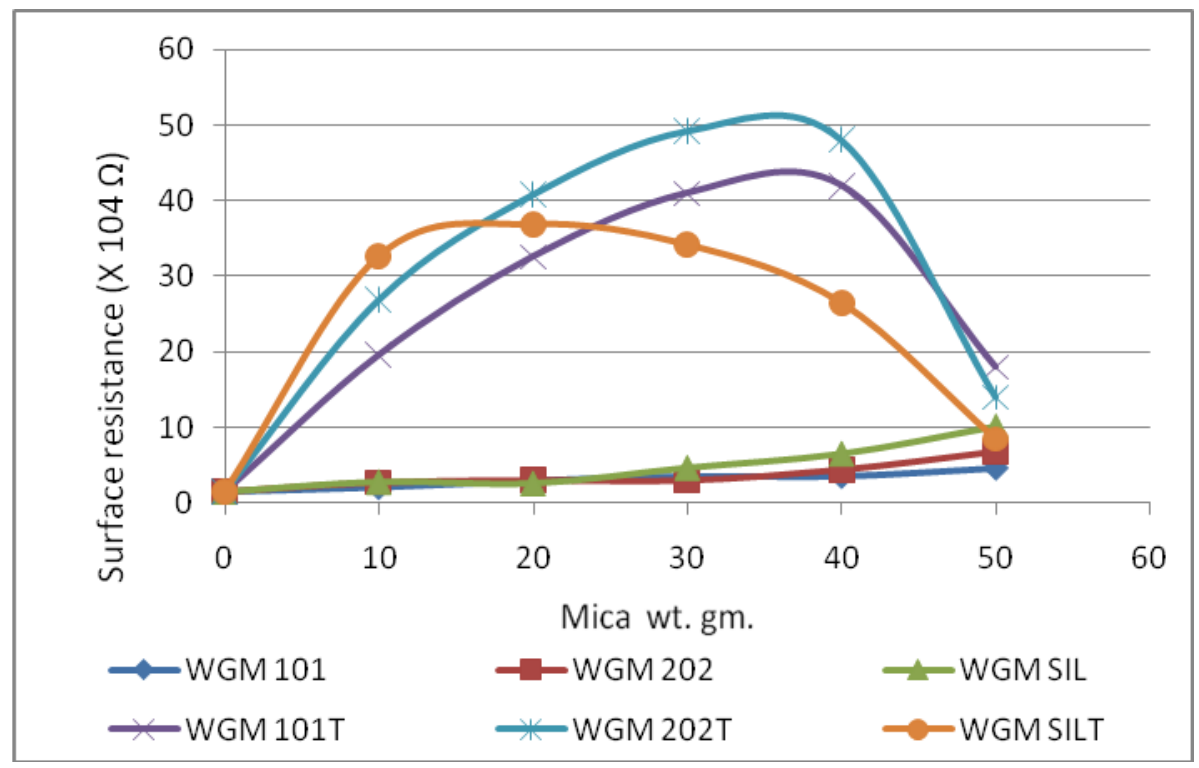

Fig. 3 Surface Resistance for Mica filled PVC Composites

It has been observed from fig.3, that there is variation in surface resistance of the composite. For the WGM SIL mica of $44 \mu \mathrm{m}$ the increase in surface resistance is 10 times more surface 
resistance of neat PVC matrix and also more as compared to mica PVC composites with mica with bigger particle size i.e. WMG 101 and WGM 202.

Arc resistance of the composite also shows variation for the 10 and 40 and 50 parts by weight(fig.4). For the 10gm weight for the WGM 101 mica filled PVC composite the reduction in the arc resistance was 40 percent The maximum rate of reduction in arc resistance is observed for the composite with 20 parts per weight for WGM 202 type mica with reduction of 45 percent compared to neat PVC matrix without filler.

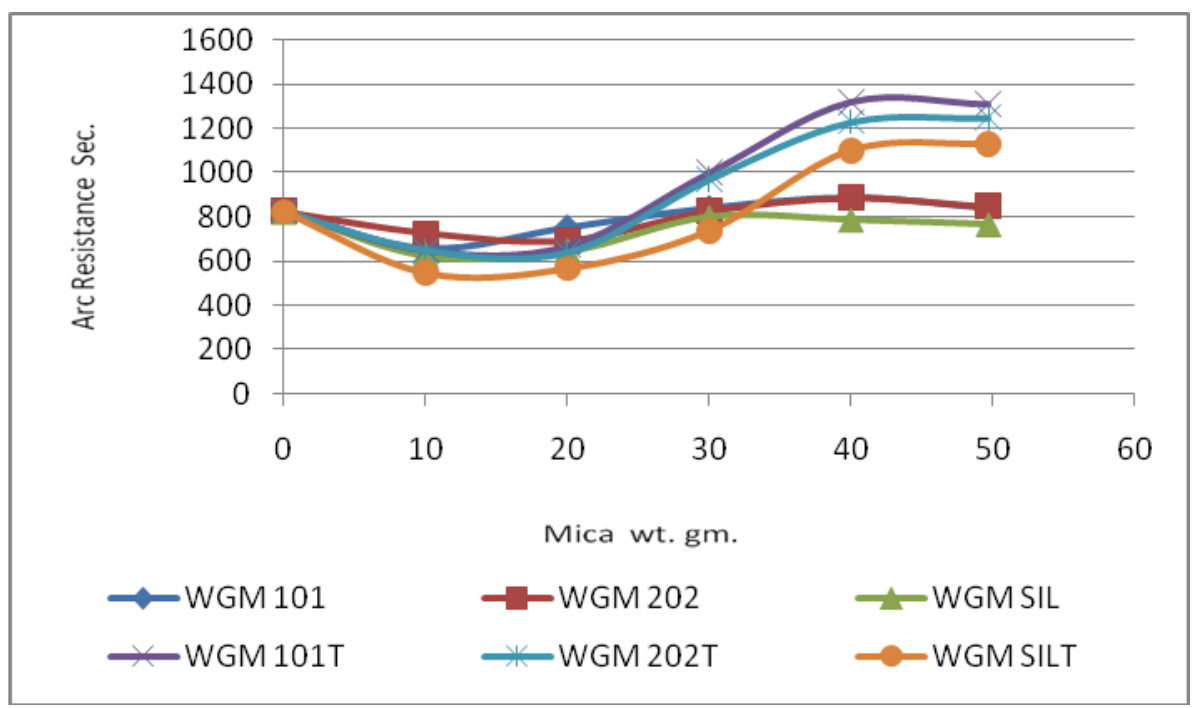

Fig. 4 Arc Resistance for Mica filled PVC Composite`

Dielectric constant defines ratio of the capacitance induced by the metallic plates with the insulator placed between them and the capacitance of the plates with vacuum between them and indicates the ability of the insulator to store electric energy. Figure 5 shows that the dielectric constant for the test pieces lies between 11 and 16 for the test samples with different concentration of untreated and treated mica PVC composites. This indicates that there is small variation in values of capacitance of the test materials making more suitable to be used as electric insulating material.

\subsection{Shore D Hardness of Test Samples}

The compression molded test samples were tested for the shore D hardness as per ASTM . The figure 6 shows that, there is about 4percent rise in the hardness of the WGM 101 mica filled PVC composite for its 10 weight percent addition where as it reduces by 14 percent when same mica is added up-to 30 weight percent in the PVC composite. For the WGM SIL mica incorporation in the PVC composite in different concentration the hardness increases by 26 percent for 30 weight percent addition where it reduces after for more filler concentration. For the WGM 202 mica addition in the composite there was marginal increase in the hardness when concentration is above 40 weight percent. In all for the untreated mica addition of different particle size and different filler concentration small increase in the shore 
D hardness indicates that the even after filler addition up-to 50 weight percent the PVC composite remains comparatively soft so can be used for cable and sheathing application. The effect of high amount of plasticizer (50grams) in the composite clearly indicates that flexibility and ductility of the composite is not affected drastically without much increase in hardness of the mica filled PVC composites. This will make it possible to use these composites for fabrication of cables and wire with affordable cost and improvement of mechanical and electrical properties.

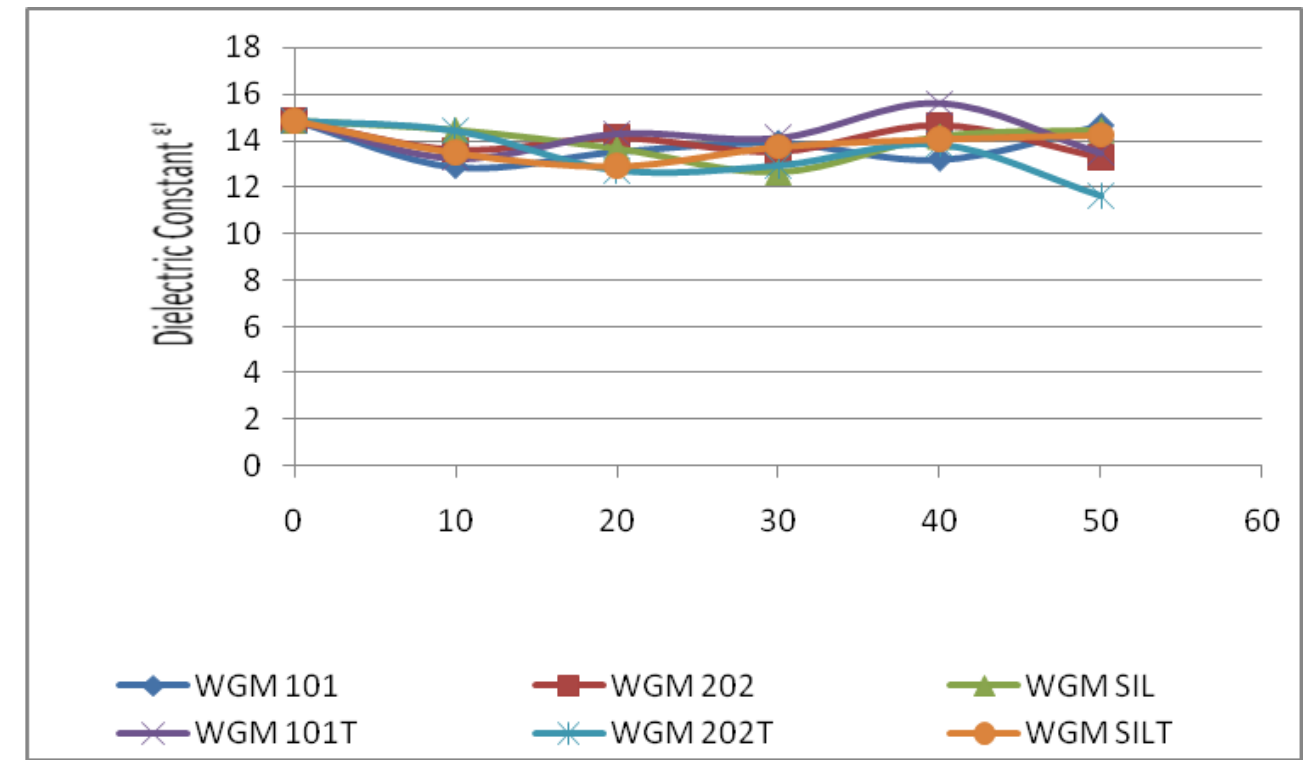

Fig. 5 Dielectric constant of mica filled PVC composites.

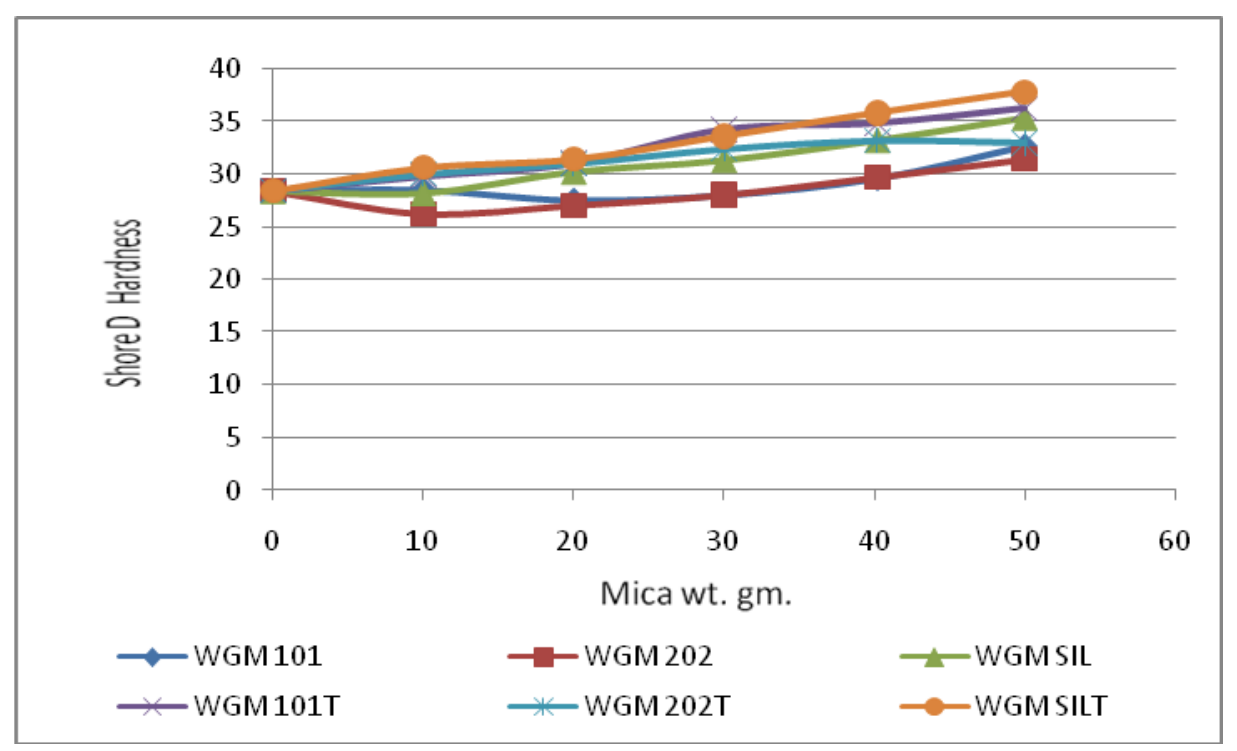

Fig.6 Shore D hardness of Mica filled PVC Composites

\subsection{Fracture Morphology}

Liquid nitrogen fractured and tensile test fractured surfaces of the mica filled PVC 
composites are shown in figure 7 to 11 . The possible origins of the crack in these composites are voids or air bubbles, resin rich areas, particle size of the fillers and poor mica and matrix adhesion. The figures 7 to 9 shows brittle fractures of the composites. For the tensile tested composite specimens (Fig. 10,11) the debonding at the interface of the mica and PVC matrix shows pullout of the mica particles showing voids of bigger size. This mainly happens due to lack of proper interfacial adhesion.

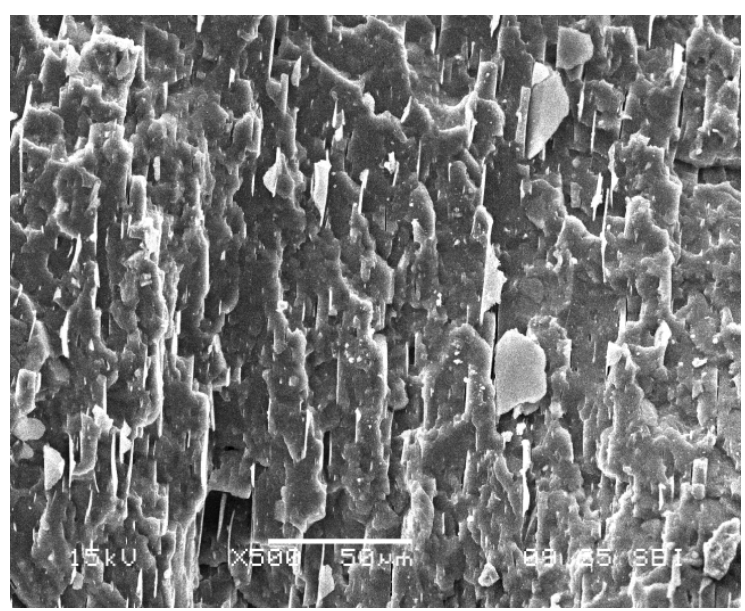

Fig. 7 SEM:SPD 11, 1K, Liquid Nitrogen Fractured, 10 phr WGM SIL mica filled PVC Composite

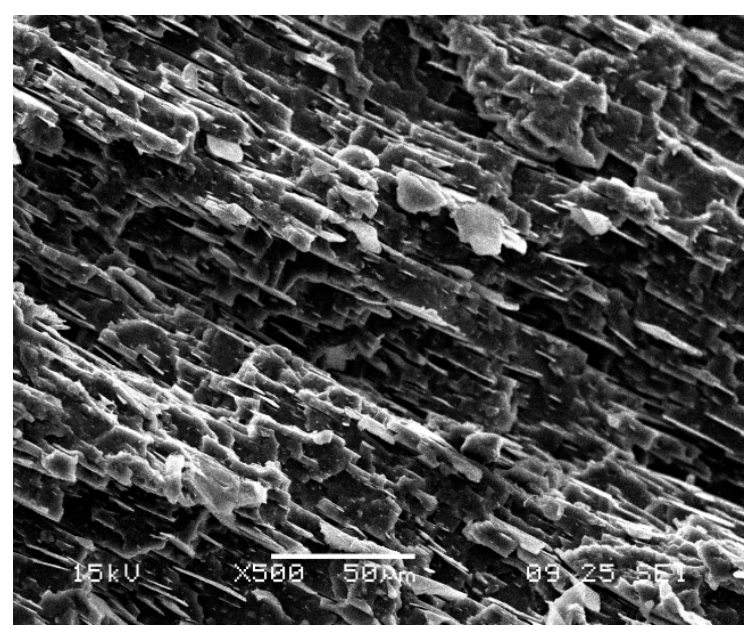

Fig. 8 SEM:SPD 13, 1K, Liquid Nitrogen Fractured,, 30 phr WGM SIL mica filled PVC Composite.

The micrographs clearly shows that the mica particles are randomly oriented and large number of particles are subjected to tensile stresses acting on the planes perpendicular to them where crack propagation takes place. As the mica is having low splitting energy it undergoes delamination. The high levels of particle pull out occur due to the low strength values and low elongation at break. 


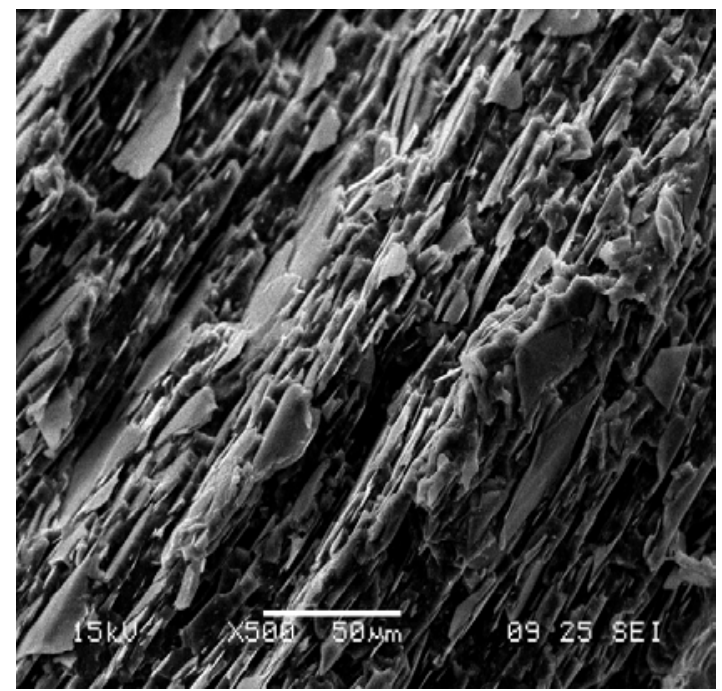

Fig. 9 SEM: SPD 15, 1K, Liquid Nitrogen Fracture d, 50 phr WGM SIL Mica filled PVC Composite.

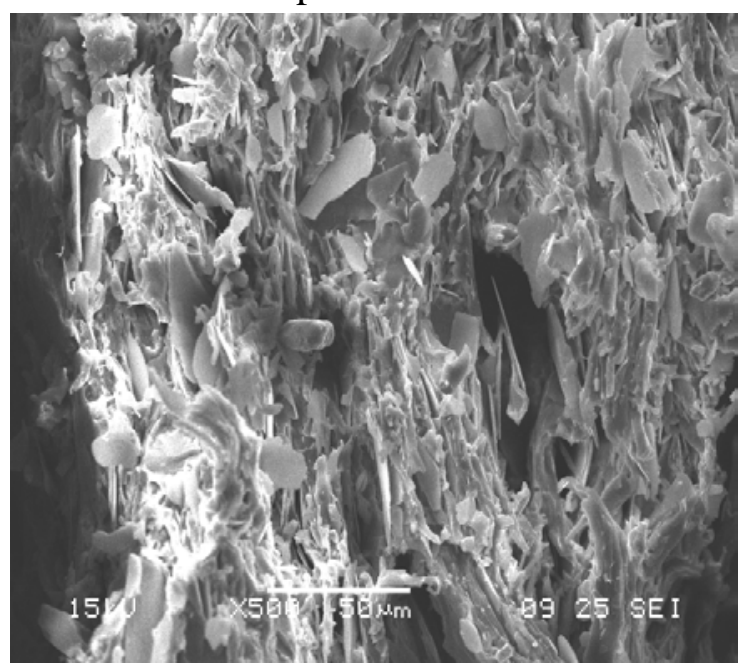

Fig. 10 SEM: SPD 13-1K Tensile tested Specimen, with 30 phr WGM SIL Mica filled PVC composite.

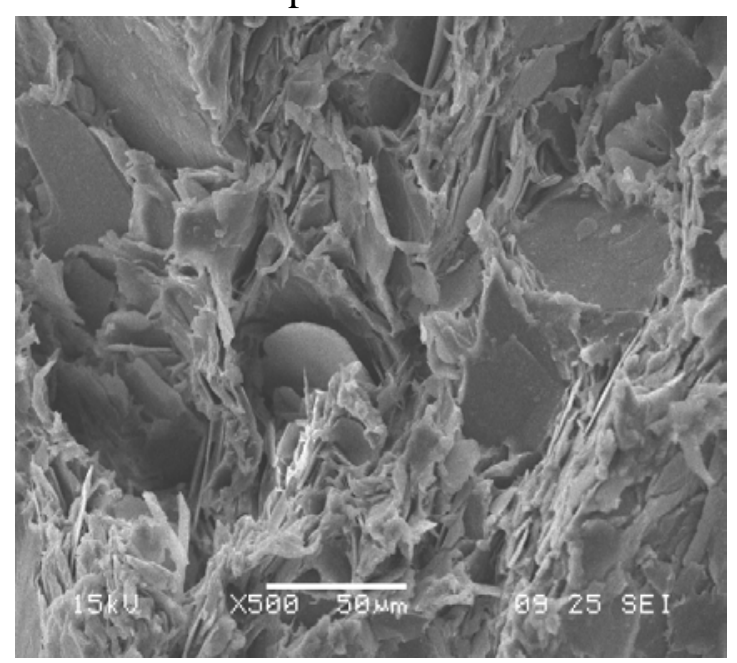

Fig. 11 SEM SPD 15 1K Tensile Tested Specimen with 50phr WGM SIL Mica Filled PVC Composite 


\section{CONCLUSION}

$>\quad$ Elongation at break of the composite reduces with higher loading of mica for treated and untreated mica filled composites. This is primarily because of interfacial stresses developed between filler and matrix at the time of curing and stressing of composite leads to micro-cracks reducing its tensile properties. This happens also because of weak filler matrix adhesion.

$>\quad$ Dielectric strength and surface resistance of composite increases up to 30 gram mica addition. Increase in these properties was slightly more for surface treated mica filled PVC composites as it improves surface treatment improves filler adhesion with polymer matrix. Higher loading of mica changes the structure of polymer matrix reducing its insulation properties.

Surface treatment of mica improves an arc resistance of composite which increases for the higher loading of treated and untreated mica in PVC matrix. It has been also observed that values of dielectric constant does not changes drastically as there is small variation in capacitance of the material.

Shore D hardness of test composite shows that even for higher loading of mica polymer retains its softness and can be used for wire and cable applications.

\section{REFERENCES}

1. P.Bataile,S.Boisee, H.P. Schreiber, J of Vinyl \& Additive Tech.,Vol.6 Issue 4, Pg.147-151, Dec. 84.

2. T. M. Malik, R. E. Prud'homme, B. Remillard, Pol. Composite, Vol. 7 Iss..5, , Pg. 315322. Oct. 1986

3. P. Bataille, T.V. Bui, Pol. Composites, Vol. 2 issue 1, pg. 8-12, Aug. 2004

4. C.J. Marshall, R. Rozett, A.C. Kunkle, Plstic Compounding, vol.8, issue 7, pg. 69-70,73, Nov.85

5. C. Richard, K. Hing, H.P. Schreiber, Pol. Composites, vol.6, Issue.4 Pg. 201-208, Aug. 2004

6. D. Maldas, B. V. Kokta, J of Vinyl 7 Addit. Tech. vol. 15, issue 1, pg. 38-44, March 1993

7. V. B. Gupta., C. Brahatheeswaran., J. Appl. Polym. Sci.. vol 52, 107- 118 (1994)

8. R. Zhao., J. Huan., B. Sun., G. Dai., J. Appl. Polym. Sci.. vol. 82, 2719 - 2728 (2001)

9. RG Raj, BV Kokta, C Daneault, J Appl. Polym. Sci. Vol 40, 645-55 (1990)

10. M. A. Osman, A. Atallah, M. Muller, U. W. Suter., Polymer,vol. 42 6545-6556,(2001)

11. Fenton,Malcom, Hawley, George, Pol. Composites, vol. V3, Issue N4, pg. 218-229, Oct.82

12 . P. Bajaj, NK Jha, Anand Kumar, J Appl. Polym. Sci. Vol 44, 1921-1930 (1992)

13. H. Ismail, Y. Munusamy, J of Reinforced Plastics \& Comp. Vol. 26. No. 16, 16811694,(2007)

14. A. Tripathi, A. K. Tripathi, P.K.C. Pillai, J of Mtl Sci. letters 9, pg. 443-45, 1990. 
15. S.P. Deshmukh, A.C. Rao, V.R. Gaval, S.Joseph, P.A. Mahanwar, J of Min.\& Mat.Cha. \& Engg, vol.9, Pg. 831-844 (2010)

16. S. P. Deshmukh, A.C. Rao, V.R. Gaval, P.A.Mahanwar, J of Ther. Comp.Mat. vol.24, iss.5 pg.583-599, Sep 2011 